\title{
PENGARUH KOMUNIKASI, BUDAYA ORGANISASI DAN LINGKUNGAN KERJA FISIK TERHADAP KEPUASAN KERJA KARYAWAN RAMADA BINTANG BALI
}

\author{
I Wayan Roy Sarlita Putra ${ }^{1}$ \\ I Gusti Ayu Dewi Adnyani² \\ ${ }^{1,2}$ Fakultas Ekonomi dan Bisnis Universitas Udayana (Unud), Bali, Indonesia \\ e-mail: wayanroysarlita@gmail.com
}

\begin{abstract}
ABSTRAK
Tujuan penelitian ini untuk mengetahui pengaruh komunikasi, budaya organisasi dan lingkungan kerja fisik terhadap kepuasan kerja karyawan pada Ramada Bintang Bali Resort and Spa. Populasi dalam penelitian ini adalah seluruh karyawan yang bekerja pada Hotel Ramada Bintang Bali Resort and Spa di Kuta. Jumlah populasi yaitu sebanyak 92 orang. Teknik penentuan sampel yang digunakan adalah metode sampel jenuh, yakni metode penentuan sampel dengan seluruh populasi dijadikan sampel penelitian, sehingga jumlah sampel responden yang digunakan adalah sebanyak 92 orang. Teknik analisis data yang digunakan dalam penelitian ini adalah analisis regresi linier berganda. Hasil penelitian menunjukkan bahwa komunikasi, budaya organisasi dan lingkungan kerja fisik berpengaruh positif dan signifikan terhadap kepuasan kerja. Hal ini berarti semakin baik komunikasi yang terjadi, semakin kuat budaya organisasi yang terbentuk dan semakin baik kondisi lingkungan kerja di Hotel Ramada Bintang Bali Resort and Spa maka akan semakin tinggi kepuasan kerja yang dirasakan pegawai.

Kata kunci: komunikasi, budaya organisasi, lingkungan kerja fisik, kepuasan kerja
\end{abstract}

\begin{abstract}
The purpose of this study was to determine the effect of communication, organizational culture and physical work environment on employee job satisfaction at the Ramada Bintang Bali Resort and Spa. The population is all employees at the Ramada Bintang Bali Resort and Spa Hotel in Kuta. The population is 92 people. The sample determination technique used is the saturated sample method, namely the method of determining the sample with the entire population made as a research sample, so that the number of samples of respondents used were 92 people. The data analysis technique used in this study is multiple linear regression analysis. The results showed that communication, organizational culture and physical work environment had a positive and significant effect on job satisfaction. This means that the better communication happens, the stronger the organizational culture is formed and the better the working environment conditions at the Ramada Bintang Bali Resort and Spa Hotel, the higher the job satisfaction that employees feel.

Keywords: communication, organizational culture, physical work environment, job satisfaction
\end{abstract}




\section{PENDAHULUAN}

Setiap Perusahaan pada umumnya pasti memiliki tujuan yang jelas, baik itu tujuan jangka pendek maupun tujuan jangka panjang. Untuk mewujudkan tujuan tersebut, perusahaan memanfaatkan berbagai faktor produksi yang dimilikinya, seperti sumber daya alam, sumber daya manusia, modal dan kemampuan. Suatu perusahaan dalam menjalankan aktivitasnya akan selalu berhadapan dengan manusia sebagai sumber daya yang dinamis dan memiliki kemampuan untuk terus berkembang. Di dalam organisasi, manusia merupakan salah satu unsur yang terpenting (Suryaningsih,2012). Oleh karena itu hendaknya organisasi memberikan arahan yang positif demi tercapainya tujuan organisasi dengan memperhatikan kepuasan kerja karyawan.

Suryaningsih (2012), menyatakan bahwa faktor-faktor yang mempengaruhi kepuasan kerja karyawan memiliki tingkat yang berbeda-beda sesuai dengan nilai yang berlaku pada dirinya. Semakin tinggi penilaian terhadap kegiatan, dirasakan sesuai dengan keinginan individu, maka semakin tinggi pula kepuasannya terhadap kegiatan. Berkaitan dengan hal tersebut faktor-faktor yang lazim dicakup dalam kepuasan kerja di lihat dari tingkat individual adalah karateristikkarateristik biografi, kepribadian dan emosi-emosi, nilai-nilai dan sikap sikap, kemampuan, persepsi, motivasi, pembelajaran individual. Dilihat dari tingkat kelompok adalah komunikasi, pembuatan keputusan kelompok, kepemimpinan dan kepercayaan, struktur kelompok, konflik, kekuatan dan politik, dan lingkungan kerja, dan tim-tim kerja. 
Komunikasi sangat penting dan merupakan kunci pembuka dalam meningkatkan kepuasan kerja karyawan. Dengan komunikasi seseorang dapat menyampaikan keinginan yang terpendam dalam hatinya kepada orang lain, baik melalui suara, bahasa tubuh, atau isyarat dan sebagainya. Semakin lancar dan cepat komunikasi yang dilakukan, akan semakin cepat pula terbinanya hubungan kerja.

Budaya organisasi juga mempengaruhi kepuasan kerja karyawan dalam suatu organisasi. Budaya organisasi adalah filosofi dasar organisasi yang memuat keyakinan, norma-norma, dan nilai-nilai bersama yang menjadi karateristik inti tentang bagaimana cara melakukan sesuatu dalam organisasi (Wibowo, 2010 : 19). Budaya organisasi dibentuk oleh para individu, dalam organisasi, etika organisasi yang dianut, hak karyawan yang diberikan kepada tiap orang dan juga jenis struktur organisasi itu sendiri. Dengan demikian budaya organisasi menjadikan anggota organisasi untuk fokus pencapaian tujuan organisasi.

Selain faktor diatas yang mempengaruhi kepuasan kerja karyawan adalah lingkungan kerja fisik. Lingkungan kerja yang kondusif akan mendorong efektivitas perusahaan dalam menjalankan aktivitasnya, serta akan menimbulkan semangat dan gairah kerja karyawan. Hal ini sangat bermanfaat bagi kelangsungan hidup perusahaan dan akan meningkatkan produktivitas sehingga tercapainya tujuan perusahaan. Karena apabila suatu lingkungan yang kurang baik seperti suara bising, suhu udara panas, kebersihan tidak terjaga dan sebagainya, dapat menurunkan kondisi fisik dan kondisi mental karyawan. Indikasi penurunan 
kondisi fisik dapat berupa kelelahan, kelesuan kerja, gangguan kesehatan atau sakit, akibat kerja bahkan kecelakaan kerja (Robbins, 2008 : 181).

Ramada Bintang Bali Resort and Spa adalah hotel berbintang lima yang terletak di kawasan Kuta Selatan, tepatnya di jalan Kartika Plaza Kuta. Ramada Bintang Bali Resort and Spa merupakan hotel berbintang lima yang berstandard internasional dengan fasilitas yang memadai. Secara teoritis kepuasan kerja karyawan tercermin dari beberapa indikator, salah satu diantaranya adalah tingkat absensi karyawan. Adapun tingkat absensi karyawan pada Ramada Bintang Bali Resort and Spa di Kuta dapat dilihat pada Tabel 1, sebagai berikut :

Tabel 1.

Tingkat Absensi Karyawan Ramada Bintang Bali Resort and Spa 2017

\begin{tabular}{lccccc}
\hline Bulan & $\begin{array}{c}\text { Jumlah } \\
\text { Pegawai }\end{array}$ & $\begin{array}{c}\text { Jumlah Hari } \\
\text { Kerja Efektif }\end{array}$ & $\begin{array}{c}\text { Total Hari Kerja } \\
\text { Efektif/ Bulan }\end{array}$ & $\begin{array}{c}\text { Total } \\
\text { Absensi }\end{array}$ & $\begin{array}{c}\text { Persentase Tingkat } \\
\text { Absensi (\%) }\end{array}$ \\
\hline A & $\mathbf{B}$ & $\mathbf{C}$ & $\mathbf{D = B x C}$ & $\mathbf{F}$ & H=F/D.100 \\
Januari & 92 & 25 & 2300 & 37 & 1.61 \\
Februari & 92 & 24 & 2208 & 35 & 1.59 \\
Maret & 92 & 25 & 2300 & 62 & 2.70 \\
April & 92 & 24 & 2208 & 73 & 3.31 \\
Mei & 92 & 26 & 2392 & 87 & 3.64 \\
Juni & 92 & 26 & 2392 & 61 & 2.55 \\
Juli & 92 & 26 & 2392 & 97 & 4.06 \\
Agustus & 92 & 25 & 2300 & 62 & 2.70 \\
September & 92 & 24 & 2208 & 89 & 2.03 \\
Oktober & 92 & 24 & 2208 & 61 & 3.76 \\
November & 92 & 25 & 2300 & 74 & 4.09 \\
Desember & 92 & 25 & 2300 & 94 & \\
\hline
\end{tabular}

Sumber : Ramada Bintang Bali Resort and Spa, 2017

Berdasarkan Tabel 1 dapat dijelaskan bahwa jumlah persentase tingkat absensi pada Ramada Bintang Bali Resort and Spa di Kuta tahun 2017 masih dianggap kurang baik memiliki nilai persentase lebih dari 3 persen. Tingkat kehadiran karyawan perbulan yang masih dianggap baik menurut Riduwan dan Sunarto (2007:17) adalah berkisar 2 sampai 3 persen, sedangkan tingkat absensi 3 persen ke atas menunjukkan rendahnya disiplin kerja karyawan. Hal ini 
mengindikasikan bahwa tingkat disiplin kerja karyawan masih perlu ditingkatkan, karena dengan banyaknya karyawan yang tidak hadir dapat menyebabkan kegiatan operasional perusahaan tidak optimal dan pekerjaan tidak dapat terselesaikan tepat waktu.

Indikasi rendahnya kepuasan kerja karyawan Ramada Bintang Bali Resort and Spa di Kuta yang masih terlihat kurang optimal dalam bekerja juga dapat dilihat dari banyaknya karyawan yang masih menggunakan jam kerja untuk istirahat, seperti pada waktu jam kerja masih ada beberapa karyawan yang mengobrol dan membaca koran sehingga tugas dan pekerjaan tidak tepat waktu, selain itu masih terdapat cukup banyak karyawan yang datang terlambat dan pulang kerja lebih awal, yang membuktikan bahwa kepuasan kerja karyawan pada Ramada Bintang Bali Resort and Spa di Kuta masih perlu ditingkatkan. Data tersebut dipaparkan pada Tabel 2 berikut:

Tabel 2.

Banyaknya Kejadian Datang Kerja Terlambat dan Pulang Kerja Lebih Awal pada Ramada Bintang Bali Resort and Spa Tahun 2017

\begin{tabular}{ccc}
\hline Bulan & \multicolumn{2}{c}{ Banyak Kejadian } \\
\cline { 2 - 3 } & $\begin{array}{c}\text { Datang } \\
\text { Terlambat }\end{array}$ & $\begin{array}{c}\text { Pulang } \\
\text { Lebih Awal }\end{array}$ \\
\hline Januari & 16 & 11 \\
Februari & 19 & 18 \\
Maret & 21 & 16 \\
April & 13 & 18 \\
Mei & 16 & 14 \\
Juni & 23 & 11 \\
Juli & 13 & 19 \\
Agustus & 16 & 18 \\
September & 20 & 11 \\
Oktober & 19 & 13 \\
November & 19 & 10 \\
Desember & 21 & 18 \\
\hline Sumber : Ramada Bintang Bali Resort and Spa, 2017
\end{tabular}


Pada Tabel 2 dapat dicermati bahwa karyawan yang datang kerja terlambat dan pulang kerja lebih awal dapat dikatakan cukup banyak, sehingga jika kejadian ini dibiarkan secara terus menerus maka tidak menutup kemungkinan nantinya akan terjadi peningkatan kejadian serupa dan menjadi suatu kebiasaan bagi karyawan. Kondisi ini perlu diperhatikan oleh pihak manajamen agar tidak terjadi secara berkelanjutan dengan cara melakukan komunikasi baik formal maupun informal dengan karyawan untuk mengurangi kejadian datang kerja terlambat dan pulang kerja lebih awal.

Permasalahan budaya organisasi yang terjadi pada Ramada Bintang Bali Resort di Kuta antara lain dalam hal kedisiplinan waktu yang masih kurang baik pelaksanaannya contohnya masih ada karyawan yang terlambat datang untuk bekerja, kurangnya inisiatif karyawan dalam mengambil keputusan menyelesaikan pekerjaan, dimana karyawan masih menunggu perintah, dan setiap dua kali seminggu Ramada Bintang Bali resort mempunyai kursus bahasa Jepang yang di khususkan bagi karyawan yang menerima tamu, tetapi karyawan malas dan merasa jenuh mengikuti kursus ini karena sudah lelah pada saat bekerja dan di tambah dengan kursus lagi sehingga sering mendapatkan keluhan dari konsumen akibat penerima tamu tidak bisa bahasa Jepang. Meskipun sudah cukup melakukan pertemuan rutin setiap harinya dengan harapan mampu menciptakan suasana keterbukaan dan suasana yang nyaman pada saat bekerja sehingga kepuasan kerja karyawan dapat terwujud, tapi masih ada beberapa keluhan dari karyawan terkait dengan komunikasi seperti intruksi yang diberikan oleh pimpinan yang bersifat mendadak dan segera, sehingga terkadang tidak 
dilaksanakan sebagaimana mestinya dan masih ada ditemukan karyawan yang tidak bertegur sapa sehingga kurangnya komunikasi antara karyawan.

Bukan hanya komunikasi saja cara untuk meningkatkan kepuasan kerja karyawan, tetapi menerapkan budaya organisasi pada perusahaan juga penting. Agar karyawan terbiasa dengan aturan - aturan yang menjadi dasar keyakinan perusahaan dengan tujuan atau manfaat untuk mengatasi semua masalah masalah yang terjadi di perusahaan. Lingkungan kerja fisik pada Ramada Bintang Bali Resort di Kuta menjadi perhatian untuk meningkatkan kepuasan kerja karyawan. Hal-hal yang menjadi perhatian dari lingkungan kerja fisik di Ramada Bintang Bali Resort di Kuta adalah ruangan, penerangan, gangguan dalam ruangan, keadaan udara (temperature atau sirkulasi udara). Ada beberapa keluhan dari karyawan mengenai lingkungan kerja fisik seperti penerangan yang kurang dan ruangan loker yang sempit menyulitkan karyawan pada saat menaruh barang di loker, sempitnya ruangan kantin karyawan, membuat pertukaran suhu udara tidak bagus sehingga menjadi pengap dan karyawan merasa tidak nyaman saat bekerja, dan areal parkir karyawan yang sempit, tidak sesuai dengan jumlah karyawan yang ada.

Adanya perhatian dan ditemui permasalah berkaitan dengan komunikasi, budaya organisasi dan lingkungan kerja fisik dalam usaha meningkatkan kepuasan kerja karyawan maka penelitian ini bertujuan untuk mengetahui pengaruh komunikasi, budaya organisasi dan lingkungan kerja fisik terhadap kepuasan kerja karyawan pada Ramada Bintang Bali Resort and Spa di Kuta Kabupaten Badung. 
Berdasarkan telaah dan kajian penelitian terdahulu, maka dapat disusun hipotesis sebagai berikut:

$\mathrm{H}_{1}$ : Komunikasi berpengaruh positif dan signifikan terhadap kepuasan kerja karyawan

$\mathrm{H}_{2}$ : Budaya organisasi berpengaruh positif dan signifikan terhadap kepuasan kerja karyawan

$\mathrm{H}_{3}$ : Lingkungan kerja fisik berpengaruh positif dan signifikan terhadap kepuasan kerja karyawan

Berdasarkan kajian penelitian terdahulu dan hipotesis yang sudah dirumuskan, maka model konseptual dalam penelitian ini adalah sebagai berikut:

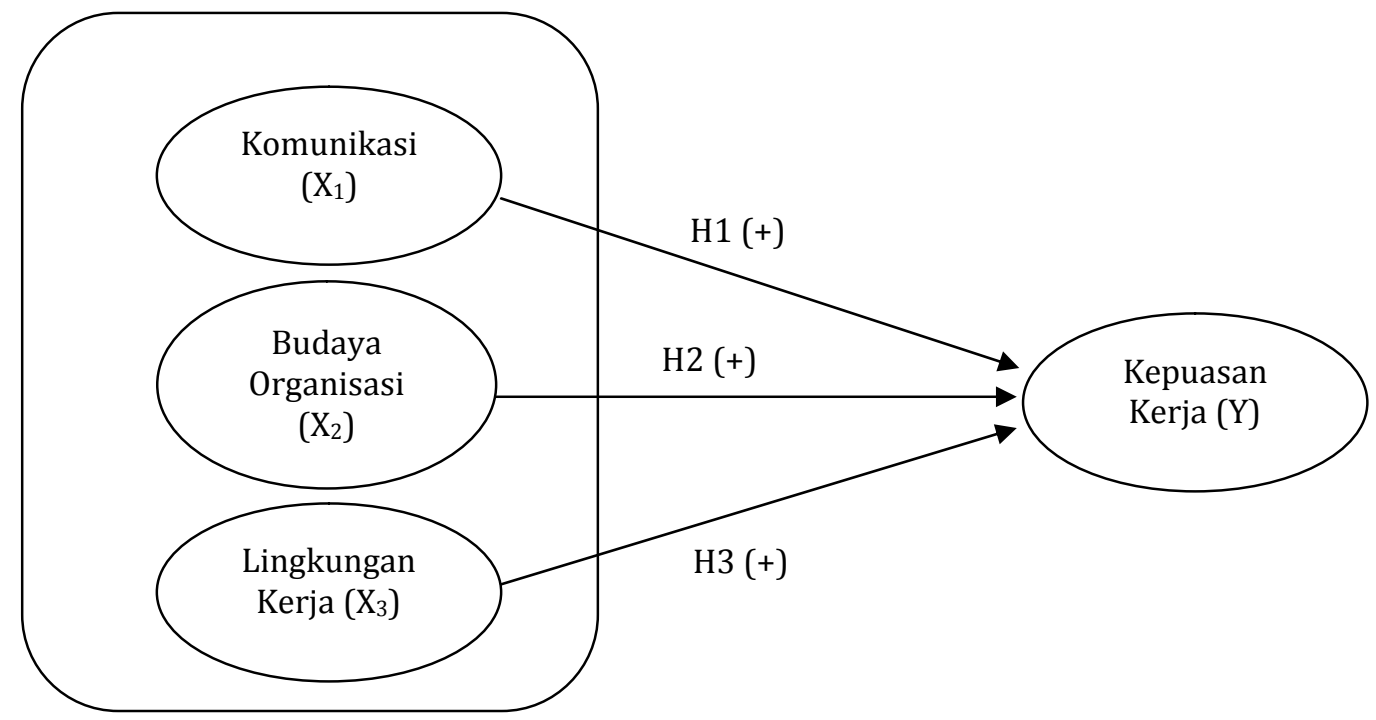

Gambar 1. Model Konseptual

Sumber : kajian penelitian terdahulu

\section{METODE PENELITIAN}

Penelitian ini digolongkan pada penelitian kuantitatif. Menurut Umar (2008:68) penelitian kuantitatif dilakukan dengan mendefinisikan, mengukur data kuantitatif dan statistik objektif melalui perhitungan ilmiah berasal dari sampel orang orang yang diminta menjawab atas sejumlah pertanyaan tentang survey untuk menentukan frekuensi dan persentase tanggapan mereka. 
Penelitian ini di lakukan di Ramada Bintang Bali Resort and Spa yang berlokasi di Jln. Kartika Plaza Kuta, Kabupaten Badung, Bali, Indonesia. Alasan dipilihnya lokasi ini, karena terdapat indikasi rendahnya kepuasan kerja karyawan yang terlihat dari tingginya tingkat absensi karyawan per bulan dan juga banyak kejadian karyawan yang data terlambat dan pulang lebih awal dari waktu yang ditentukan.

Penelitian ini menggunakan dua jenis variabel yaitu variabel bebas, dan variabel terikat, yang secara rinci dirangkum dalam Tabel 3.

Tabel 3.

Rangkuman Variabel dan Indikator Penelitian

\begin{tabular}{|c|c|c|c|}
\hline No. & Variabel & Indikator & Referensi \\
\hline 1. & $\begin{array}{c}\text { Komunikasi } \\
\left(\mathrm{X}_{1}\right)\end{array}$ & $\begin{array}{l}\text { 1. penyampaian informasi pekerjaan oleh pimpinan } \\
\text { sudah efektif } \\
\text { 2. penyampaian informasi dari para pegawai terhadap } \\
\text { pimpinan tentang pengambilan keputusan sudah baik } \\
\text { 3. diskusi yang terjadi antar pegawai dalam menemukan } \\
\text { solusi permasalahan berjalan efektif } \\
\text { 4. penyampaian informasi terkait pekerjaan yang terjadi } \\
\text { di luar jam kerja sudah efektif }\end{array}$ & $\begin{array}{c}\text { Mariani dan } \\
\text { Sariyathi } \\
(2017)\end{array}$ \\
\hline 2. & $\begin{array}{l}\text { Budaya } \\
\text { Organisasi } \\
\quad(\mathrm{X} 2)\end{array}$ & $\begin{array}{l}\text { 1. Inovatif memperhitungkan resiko } \\
\text { 2. Memberikan perhatian pada setiap masalah secara } \\
\text { detail didalam melakukan pekerjaan } \\
\text { 3. Berorientasi pada hasil yang akan dicapai } \\
\text { 4. Berorientasi kepada semua kepentingan karyawan } \\
\text { 5. Hadir tepat waktu dalam bekerja } \\
\text { 6. Mempertahankan dan menjaga stabilitas kerja }\end{array}$ & $\begin{array}{l}\text { Julianto dan } \\
\text { Hendriani } \\
\text { (2014) }\end{array}$ \\
\hline 3. & $\begin{array}{c}\text { Lingkungan } \\
\text { Kerja Fisik } \\
\text { (X3) }\end{array}$ & $\begin{array}{l}\text { 1. persepsi karyawan mengenai suasana kerja } \\
\text { 2. persepsi karyawan mengenai hubungan dengan rekan } \\
\text { kerja } \\
\text { 3. persepsi karyawan mengenai tersedianya fasilitas } \\
\text { kerja }\end{array}$ & $\begin{array}{c}\text { Santoso } \\
(2018)\end{array}$ \\
\hline 4 & $\begin{array}{l}\text { Kepuasan } \\
\text { Kerja } \\
\text { Karyawan } \\
(\mathrm{Y})\end{array}$ & $\begin{array}{l}\text { 1. Pekerjaan itu sendiri (the work it self) } \\
\text { 2. Rekan kerja (Co-workers) } \\
\text { 3. Kesempatan mendapatkan promosi jabatan } \\
\text { (promotion opportunities) } \\
\text { 4. Bayaran (pay) } \\
\text { 5. Kondisi kerja (Work condition) }\end{array}$ & $\begin{array}{l}\text { Cekmecelio } \\
\text { glu et al. } \\
\text { (2012) }\end{array}$ \\
\hline
\end{tabular}

Populasi dalam penelitian ini adalah seluruh karyawan yang bekerja pada

Hotel Ramada Bintang Bali Resort and Spa di Kuta. Jumlah populasi dalam 
penelitian ini yaitu sebanyak 92 orang. Teknik sampel yang digunakan di dalam penelitian ini adalah sampling jenuh. Menurut Sugiyono (2016:153) sampling jenuh adalah teknik penentuan sampel apabila semua anggota populasi ingin digunakan sebagai sampel, hal ini sering dilakukan bila jumlah populasi relatif kecil, atau penelitian yang ingin membuat generalisasi dengan kesalahan yang sangat kecil.

Penelitian ini menggunakan teknik analisis data, yaitu dengan analisis regresi linier berganda. Analisis regresi linier berganda bertujuan untuk mengetahui besarnya pengaruh komunikasi, budaya organisasi dan lingkungan kerja fisik terhadap kepuasan kerja karyawan pada Ramada Bintang Bali Resort and Spa, di Kuta. Persamaan matematis untuk hubungan yang dihipotesiskan dapat dirumuskan sebagai berikut :

$Y=\alpha+b_{1} X_{1}+b_{2} X_{2}+e$

Keterangan:

$\mathrm{Y} \quad=$ kepuasan kerja karyawan

a $\quad=$ konstanta

$\mathrm{b}_{1} \quad=$ koefisien regresi variabel komunikasi

$\mathrm{b}_{2} \quad=$ koefisien regresi variabel budaya organisasi

$\mathrm{b}_{3} \quad=$ koefisien regresi variabel lingkungan kerja fisik

$\mathrm{X}_{1} \quad=$ komunikasi

$\mathrm{X}_{2} \quad$ = budaya organisasi

$\mathrm{X}_{3} \quad=$ lingkungan kerja fisik

$\mathrm{e} \quad=$ Error

\section{HASIL DAN PEMBAHASAN}

Data penelitian diperoleh dari hasil kuesioner yang telah disebarkan kepada responden penelitian sejumlah 92 orang karyawan Hotel Ramada Bintang Bali 
Resort and Spa. Karakteristik responden meliputi jenis kelamin, umur, tingkat pendidikan dan lama kerja responden. Ringkasan mengenai karakteristik responden dapat dilihat pada Tabel 4 berikut ini.

Tabel 4.

Karakteristik karyawan Hotel Ramada Bintang Bali Resort and Spa

\begin{tabular}{|c|c|c|c|c|}
\hline No & Karakteristik & Klasifikasi & $\begin{array}{c}\text { Jumlah } \\
\text { Responden } \\
\text { (orang) }\end{array}$ & $\begin{array}{c}\text { Persentase } \\
\text { Responden } \\
(\%)\end{array}$ \\
\hline \multirow{3}{*}{1} & \multirow{2}{*}{ Jenis Kelamin } & Laki-laki & 55 & 59,78 \\
\hline & & Perempuan & 37 & 40,22 \\
\hline & \multicolumn{2}{|c|}{ Jumlah } & 92 & 100 \\
\hline \multirow{5}{*}{2} & \multirow{4}{*}{ Umur } & 21 - 30 Tahun & 22 & 23,91 \\
\hline & & 31 - 40 Tahun & 37 & 40,22 \\
\hline & & $40-50$ Tahun & 24 & 26,09 \\
\hline & & $>50$ Tahun & 9 & 9,78 \\
\hline & \multicolumn{2}{|c|}{ Jumlah } & 92 & 100 \\
\hline \multirow{5}{*}{3} & \multirow{4}{*}{$\begin{array}{c}\text { Jenjang } \\
\text { Pendidikan } \\
\text { Terakhir }\end{array}$} & SMA & 25 & 27,17 \\
\hline & & Diploma & 21 & 22,83 \\
\hline & & Sarjana & 39 & 42,39 \\
\hline & & Pascasarjana & 7 & 7,61 \\
\hline & \multicolumn{2}{|c|}{ Jumlah } & 92 & 100 \\
\hline \multirow{4}{*}{4} & \multirow{3}{*}{ Lama Kerja } & $1-5$ tahun & 37 & 40,22 \\
\hline & & 5-10 tahun & 45 & 48,91 \\
\hline & & $>10$ tahun & 10 & 10,87 \\
\hline & \multicolumn{2}{|c|}{ Jumlah } & 92 & 100 \\
\hline
\end{tabular}

Sumber : Hasil pengolahan data primer, 2018

Tabel 4 menunjukkan lebih banyak pegawai laki-laki dibandingkan perempuan yang bekerja di Hotel Ramada Bintang Bali Resort and Spa. Dilihat dari segi usia, menunjukkan bahwa pegawai yang bekerja di Hotel Ramada Bintang Bali Resort and Spa mayoritas adalah yang berusia 31-40 tahun. Data juga menunjukkan bahwa karyawan di Hotel Ramada Bintang Bali Resort and Spa paling dominan adalah lulusan Sarjana yang dianggap sudah mampu serta memadai untuk menjadi karyawan hotel yang memiliki kompetensi untuk mencapai tujuan organisasi.

Pengelompokkan responden berdasarkan masa kerja menunjukkan bahwa sebagian besar karyawan di Hotel Ramada Bintang Bali Resort and Spa memiliki masa kerja 5 
sampai 10 tahun yang menunjukkan bahwa pegawai Hotel Ramada Bintang Bali Resort and Spa memiliki komitmen organisasi yang tinggi, karena mampu bertahan bekerja selama lebih dari 5 tahun.

Hasil rekapitulasi uji validitas dan reliabilitas dalam penelitian ini disajikan dalam Tabel 5 sebagai berikut:

Tabel 5.

Rekapitulasi Hasil Uji Validitas dan Reliabilitas Instrumen Penelitian

\begin{tabular}{ccccc}
\hline Variabel & Indikator & $\begin{array}{c}\text { Koefisien } \\
\text { Korelasi }\end{array}$ & $\begin{array}{c}\text { Cronbadh's } \\
\text { Alpha }\end{array}$ & Keterangan \\
\hline \multirow{3}{*}{ Komunikasi } & $\mathrm{X}_{1.1}$ & 0,854 & & Valid dan reliabel \\
$\left(\mathrm{X}_{1}\right)$ & $\mathrm{X}_{1.2}$ & 0,856 & 0,823 & Valid dan reliabel \\
& $\mathrm{X}_{1.3}$ & 0,852 & & Valid dan reliabel \\
& $\mathrm{X}_{1.4}$ & 0,741 & & Valid dan reliabel \\
& $\mathrm{X}_{2.1}$ & 0,781 & & Valid dan reliabel \\
Budaya organisasi & $\mathrm{X}_{2.2}$ & 0,739 & & Valid dan reliabel \\
$\left(\mathrm{X}_{2}\right)$ & $\mathrm{X}_{2.3}$ & 0,723 & \multirow{2}{*}{0,782} & Valid dan reliabel \\
& $\mathrm{X}_{2.4}$ & 0,745 & & Valid dan reliabel \\
& $\mathrm{X}_{2.5}$ & 0,714 & & Valid dan reliabel \\
Lingkungan kerja & $\mathrm{X}_{2.6}$ & 0,658 & & Valid dan reliabel \\
$\left(\mathrm{X}_{3}\right)$ & $\mathrm{X}_{3.1}$ & 0,819 & & Valid dan reliabel \\
& $\mathrm{X}_{3.2}$ & 0,865 & 0,833 & Valid dan reliabel \\
& $\mathrm{X}_{3.3}$ & 0,769 & & Valid dan reliabel \\
& $\mathrm{Y}_{1}$ & 0,689 & & Valid dan reliabel \\
Kepuasan kerja (Y) & $\mathrm{Y}_{2}$ & 0,809 & & Valid dan reliabel \\
& $\mathrm{Y}_{3}$ & 0,812 & 0,791 & Valid dan reliabel \\
& $\mathrm{Y}_{4}$ & 0,633 & & Valid dan reliabel \\
& $\mathrm{Y}_{5}$ & 0,791 & & Valid dan reliabel \\
\hline Sumber : Data diolah, 2018 & & & &
\end{tabular}

Hasil uji validitas pada tabel 5 menunjukkan bahwa seluruh instrumen penelitian yang digunakan untuk mengukur variabel komunikasi, budaya organisasi, lingkungan kerja, dan kepuasan kerja memiliki nilai koefisien korelasi dengan skor total seluruh item pernyataan lebih besar dari 0,30 dan memiliki koefisien Cronbach's Alpha lebih dari 0,60. Hal ini menunjukkan bahwa butirbutir pernyataan dalam instrument penelitian tersebut valid dan reliabel, sehingga layak digunakan sebagai instrument penelitian. 
Variabel komunikasi diukur dengan menggunakan 4 indikator yang disesuaikan dengan kondisi di Hotel Ramada Bintang Bali Resort and Spa, seperti yang ditunjukan dalam Tabel 6.

Tabel 6.

Deskripsi Penilaian Responden Terhadap Variabel Komunikasi

\begin{tabular}{|c|c|c|c|c|c|c|c|}
\hline \multirow[t]{2}{*}{ Indikator } & \multicolumn{5}{|c|}{$\begin{array}{c}\text { Frekuensi Jawaban } \\
\text { Responden }\end{array}$} & \multirow{2}{*}{$\begin{array}{l}\text { Rata - } \\
\text { Rata }\end{array}$} & \multirow[t]{2}{*}{ Keterangan } \\
\hline & 1 & 2 & 3 & 4 & 5 & & \\
\hline $\begin{array}{l}\text { Penyampaian informasi pekerjaan } \\
\text { oleh pimpinan }\left(\mathrm{X}_{1.1}\right)\end{array}$ & 1 & 4 & 12 & 55 & 20 & 3,97 & Baik \\
\hline $\begin{array}{l}\text { Penyampaian informasi dari para } \\
\text { pegawai terhadap pimpinan }\left(\mathrm{X}_{1.2}\right)\end{array}$ & 2 & 3 & 20 & 38 & 29 & 3,97 & Baik \\
\hline $\begin{array}{l}\text { Diskusi yang terjadi antar pegawai } \\
\left(\mathrm{X}_{1.3}\right)\end{array}$ & 1 & 7 & 30 & 42 & 12 & 3,62 & Baik \\
\hline $\begin{array}{l}\text { Penyampaian informasi terkait } \\
\text { pekerjaan yang terjadi di luar jam } \\
\text { kerja }\left(\mathrm{X}_{1.4}\right)\end{array}$ & 0 & 5 & 18 & 45 & 24 & 3,96 & Baik \\
\hline \multicolumn{6}{|c|}{ Rata-rata Skor Variabel Komunikasi } & 3,87 & Baik \\
\hline
\end{tabular}

Sumber: Data primer diolah, 2018

Hasil analisis deksriptif sebagaimana disajikan pada tabel 6 menunjukkan bahwa variabel komunikasi secara keseluruhan memperoleh nilai rata-rata sebesar 3,87, yang berarti bahwa sebagian besar pegawai merasa jika komunikasi pada Hotel Ramada Bintang Bali Resort and Spa sudah berjalan dengan baik. Indikator yang memiliki nilai paling tinggi adalah indikator penyampaian informasi pekerjaan oleh pimpinan, dan penyampaian informasi dari para pegawai terhadap pimpinan dengan nilai rata-rata jawaban responden sebesar 3,97. Hal tersebut disebabkan karena penyampaian informasi pekerjaan yang dilakukan oleh pimpinan kepada karyawannya dan dari para karyawan terhadap pimpinan dalam pengambilan keputusan di Hotel Ramada Bintang Bali Resort and Spa sudah terlaksana dengan baik. Hal ini memberikan informasi bahwa koordinasi dan proses penyampaian komunikasi yang terjadi diantara pimpinan dan karyawan 
sudah berjalan dengan efektif, sehingga komunikasi yang terjadi pada Hotel Ramada Bintang Bali Resort and Spa mampu terbentuk dengan baik.

Skor rata-rata terendah pada variabel komunikasi terdapat pada indikator diskusi yang terjadi antar pegawai dengan nilai rata-rata sebesar 3,62. Indikator diskusi yang terjadi antar pegawai sudah memperoleh penilaian yang baik dari karyawan berdasarkan hasil kuisioner, namun masih lebih rendah dari nilai ratarata variabel komunikasi. Hal tersebut menunjukkan bahwa masih ada beberapa orang pegawai yang merasa bahwa diskusi antar pegawai dalam menemukan solusi permasalahan belum berjalan dengan efektif. Oleh karena itu, dalam upaya meningkatkan komunikasi menjadi lebih baik, maka Hotel Ramada Bintang Bali Resort and Spa sebaiknya memberikan pelatihan dan pendidikan bagi karyawannya mengenai cara berdiskusi yang tepat dalam menemukan solusi pada permasalahan kerja yang dihadapi. Apabila karyawan mampu berdiskusi dengan efektif dalam menemukan solusi permasalahan pekerjaan, maka komunikasi akan semakin baik.

Variabel budaya organisasi diukur dengan menggunakan 6 indikator yang disesuaikan dengan kondisi budaya organisasi di Hotel Ramada Bintang Bali Resort and Spa, seperti yang ditunjukan dalam Tabel 7. Hasil analisis deksriptif sebagaimana disajikan pada tabel 7 menunjukkan bahwa variabel budaya organisasi secara keseluruhan memperoleh nilai rata-rata sebesar 3,93, yang berarti bahwa Hotel Ramada Bintang Bali Resort and Spa sudah memiliki budaya organisasi yang baik. Indikator yang memiliki nilai paling tinggi adalah indikator inovatif. Hal tersebut disebabkan karena sebagian besar responden di Hotel 
Ramada Bintang Bali Resort and Spa selalu menciptakan ide-ide yang inovatif dalam pekerjaan. Selain itu, karyawan juga teliti dan cermat dalam melaksanakan tugas serta bekerja sesuai tujuan yang diberikan perusahaan, sehingga budaya organisasi mampu terbentuk dengan baik.

\section{Tabel 7.}

Deskripsi Penilaian Responden Terhadap Variabel Budaya Organisasi

\begin{tabular}{|c|c|c|c|c|c|c|c|}
\hline \multirow{2}{*}{ Indikator } & \multicolumn{5}{|c|}{$\begin{array}{c}\text { Frekuensi Jawaban } \\
\text { Responden }\end{array}$} & \multirow{2}{*}{$\begin{array}{l}\text { Rata - } \\
\text { Rata }\end{array}$} & \multirow{2}{*}{ Keterangan } \\
\hline & 1 & 2 & 3 & 4 & 5 & & \\
\hline \multirow{3}{*}{$\begin{array}{l}\text { Inovatif }\left(\mathrm{X}_{2.1}\right) \\
\text { Memberikan perhatian }\left(\mathrm{X}_{2.2}\right) \\
\text { Tanggung jawab yang tinggi }\left(\mathrm{X}_{2.3}\right)\end{array}$} & 0 & 6 & 17 & 40 & 29 & 4,00 & Baik \\
\hline & 0 & 3 & 23 & 39 & 27 & 3,98 & Baik \\
\hline & 1 & 5 & 22 & 31 & 33 & 3,98 & Baik \\
\hline \multirow{2}{*}{$\begin{array}{l}\text { Berorientasi kepada semua } \\
\text { kepentingan karyawan }\left(\mathrm{X}_{2.4}\right) \\
\text { Hadir tepat waktu }\left(\mathrm{X}_{2.5}\right)\end{array}$} & 0 & 4 & 24 & 38 & 26 & 3,93 & Baik \\
\hline & 3 & 3 & 22 & 46 & 18 & 3,79 & Baik \\
\hline $\begin{array}{l}\text { Mempertahankan stabilitas kerja } \\
\left(\mathrm{X}_{2.6}\right)\end{array}$ & 1 & 6 & 23 & 34 & 28 & 3,89 & Baik \\
\hline \multicolumn{6}{|c|}{ Rata-rata Skor Variabel Budaya organisasi } & $\mathbf{3 , 9 3}$ & Baik \\
\hline
\end{tabular}

Sumber: Data primer diolah, 2018

Skor rata-rata terendah pada variabel budaya organisasi terdapat pada indikator hadir tepat waktu dengan nilai rata-rata sebesar 3,79. Indikator hadir tepat waktu sudah memperoleh penilaian yang baik dari karyawan berdasarkan hasil kuisioner, namun masih lebih rendah dari nilai rata-rata variabel budaya organisasi. Hal tersebut menunjukkan bahwa masih ada beberapa orang karyawan di Hotel Ramada Bintang Bali Resort and Spa yang tidak mampu selalu hadir tepat waktu saat bekerja. Oleh karena itu, dalam upaya meningkatkan budaya organisasi pegawai, maka Hotel Ramada Bintang Bali Resort and Spa sebaiknya membuat sanksi yang lebih tegas bagi karyawan yang kurang disiplin dan tidak hadir tepat waktu dalam bekerja. Dengan pemberian sanksi yang tegas bagi karyawan yang melanggar, diharapkan dapat membuat karyawan jera sehingga budaya organisasi yang disiplin dapat terbentuk dengan baik. 
Variabel lingkungan kerja diukur dengan menggunakan 3 indikator yang disesuaikan dengan kondisi di Hotel Ramada Bintang Bali Resort and Spa seperti yang ditunjukan dalam Tabel 8.

\section{Tabel 8.}

Deskripsi Penilaian Responden Terhadap Variabel Lingkungan kerja

\begin{tabular}{|c|c|c|c|c|c|c|c|}
\hline \multirow[t]{2}{*}{ Indikator } & \multicolumn{5}{|c|}{$\begin{array}{c}\text { Frekuensi Jawaban } \\
\text { Responden } \\
\end{array}$} & \multirow{2}{*}{$\begin{array}{c}\text { Rata - } \\
\text { Rata }\end{array}$} & \multirow[t]{2}{*}{ Keterangan } \\
\hline & 1 & 2 & 3 & 4 & 5 & & \\
\hline Suasana kerja $\left(\mathrm{X}_{3.1}\right)$ & 1 & 8 & 15 & 48 & 20 & 3,85 & Baik \\
\hline $\begin{array}{l}\text { Hubungan dengan rekan kerja } \\
\left(\mathrm{X}_{3.2}\right)\end{array}$ & 1 & 7 & 9 & 43 & 32 & 4,07 & Baik \\
\hline Tersedianya fasilitas kerja $\left(\mathrm{X}_{3.3}\right)$ & 3 & 4 & 29 & 33 & 23 & 3,75 & Baik \\
\hline \multicolumn{6}{|c|}{ Rata-rata Skor Variabel Lingkungan kerja } & 3,88 & Baik \\
\hline
\end{tabular}

Sumber: Data primer diolah, 2018

Hasil analisis deksriptif sebagaimana disajikan pada tabel 8 menunjukkan bahwa variabel lingkungan kerja secara keseluruhan memperoleh nilai rata-rata sebesar 3,88, yang berarti bahwa sebagian besar karyawan menilai bahwa Hotel Ramada Bintang Bali Resort and Spa memiliki lingkungan kerja yang baik. Dari 3 indikator yang digunakan untuk mengukur lingkungan kerja, maka terdapat 1 indikator yang nilainya berada di atas nilai rata-rata (3.88) variabel lingkungan kerja yaitu indikator hubungan dengan rekan kerja. Hal tersebut disebabkan karena karyawan Hotel Ramada Bintang Bali Resort and Spa selama ini merasakan suasana hubungan yang baik antara teman kerja.

Skor rata-rata terendah pada variabel lingkungan kerja terdapat pada indikator tersedianya fasilitas kerja. Indikator fasilitas kerja sudah memperoleh penilaian yang baik dari karyawan berdasarkan hasil kuisioner, namun masih lebih rendah dari nilai rata-rata variabel lingkungan kerja. Hal tersebut menunjukkan bahwa masih ada beberapa orang karyawan yang merasa bahwa fasilitas yang disediakan Hotel Ramada Bintang Bali Resort and Spa dalam menunjang 
pekerjaan kurang lengkap. Oleh karena itu, dalam upaya meningkatkan lingkungan kerja menjadi lebih baik, maka pihak manajemen Hotel Ramada Bintang Bali Resort and Spa sebaiknya rutin melakukan evaluasi terhadap fasilitas yang disediakan Hotel dalam menunjang pekerjaan karyawannya. Apabila ada fasilitas yang sudah rusak segera diperbaiki atau diganti, sehingga dapat membuat karyawan merasa nyaman dalam bekerja dan pada akhirnya dapat membentuk kepuasan kerja karyawan.

Variabel Kepuasan kerja diukur dengan menggunakan 5 indikator yang disesuaikan dengan kondisi kepuasan kerja pegawai di Hotel Ramada Bintang Bali Resort and Spa seperti yang ditunjukan dalam Tabel 9.

Tabel 9.

Deskripsi Penilaian Responden Pada Variabel Kepuasan Kerja

\begin{tabular}{|c|c|c|c|c|c|c|c|}
\hline \multirow{2}{*}{ Indikator } & \multicolumn{5}{|c|}{$\begin{array}{c}\text { Frekuensi Jawaban } \\
\text { Responden }\end{array}$} & \multirow{2}{*}{$\begin{array}{l}\text { Rata - } \\
\text { Rata }\end{array}$} & \multirow[t]{2}{*}{ Keterangan } \\
\hline & 1 & 2 & 3 & 4 & 5 & & \\
\hline $\begin{array}{l}\text { Pekerjaan itu sendiri (the work it } \\
\text { self) }\left(\mathrm{Y}_{1}\right)\end{array}$ & 0 & 7 & 23 & 40 & 22 & 3,84 & Tinggi \\
\hline Rekan kerja (Co-workers) $\left(\mathrm{Y}_{2}\right)$ & 2 & 2 & 16 & 37 & 35 & 4,10 & Tinggi \\
\hline $\begin{array}{l}\text { Kesempatan promosi (Promotion } \\
\text { opportunities) }\left(\mathrm{Y}_{3}\right)\end{array}$ & 1 & 4 & 24 & 35 & 28 & 3,92 & Tinggi \\
\hline Bayaran (pay) $\left(\mathrm{Y}_{4}\right)$ & 1 & 8 & 19 & 40 & 24 & 3,85 & Tinggi \\
\hline $\begin{array}{l}\text { Kondisi kerja (Work condition) } \\
\left(\mathrm{Y}_{5}\right)\end{array}$ & 0 & 3 & 17 & 49 & 23 & 4,00 & Tinggi \\
\hline \multicolumn{6}{|c|}{ Rata-rata Skor Variabel Kepuasan Kerja } & 3,94 & Tinggi \\
\hline
\end{tabular}

Sumber: Data primer diolah, 2018

Hasil analisis deksriptif sebagaimana disajikan pada tabel 9 menunjukkan bahwa variabel kepuasan kerja secara keseluruhan memperoleh nilai rata-rata sebesar 3,94, yang berarti bahwa sebagian besar pegawai pada Hotel Ramada Bintang Bali Resort and Spa memiliki kepuasan kerja yang tinggi. Indikator yang memiliki nilai paling tinggi adalah indikator rekan kerja (co-workers). Hal 
tersebut disebabkan karena karyawan Hotel Ramada Bintang Bali Resort and Spa puas dengan rekan kerja yang mampu membuat saya termotivasi dalam bekerja

Skor rata-rata terendah pada variabel kepuasan kerja terdapat pada indikator bayaran (pay) dengan nilai rata-rata sebesar 3,85. Indikator bayaran sudah memperoleh penilaian yang baik dari karyawan berdasarkan hasil kuisioner, namun masih lebih rendah dari nilai rata-rata variabel kepuasan kerja. Hal tersebut menunjukkan bahwa masih ada beberapa orang karyawan yang merasa kurang puas dengan gaji atau upah yang diberikan oleh perusahaan. Oleh karena itu, dalam upaya meningkatkan kepuasan kerja pegawai menjadi lebih baik, maka pihak manajemen Hotel Ramada Bintang Bali Resort and Spa sebaiknya melakukan evaluasi pada gaji atau upah yang sudah diberikan pada karyawannya apakah sudah sesuai dengan beban kerja yang diterima. Apabila karyawan merasa puas dengan bayaran yang diberikan oleh perusahan karena sudah adil dan sudah sesuai sama beban kerja yang diterima, maka hal tersebut dapat meningkatkan kepuasan kerja karyawan.

Model regresi akan lebih tepat digunakan dan menghasilkan perhitungan yang lebih akurat, apabila beberapa asumsi berikut dapat terpenuhi. Uji asumsi klasik yang harus dipenuhi pada analisis regresi linear sederhana antara lain Uji Normalitas, Uji Multikolenearitas dan Uji Heterokedastisitas yang dirangkum dalam Tabel 10 berikut ini: 
Tabel 10.

Rangkuman Hasil Uji Asumsi Klasik

\begin{tabular}{cclccc}
\hline \multirow{2}{*}{$\begin{array}{c}\text { Hasil Uji } \\
\text { Normalitas }\end{array}$} & & \multicolumn{1}{c}{ Variabel } & \multicolumn{2}{c}{$\begin{array}{c}\text { Hasil Uji } \\
\text { Multikolinieritas }\end{array}$} & $\begin{array}{c}\text { Hasil Uji } \\
\text { Heteroskedastisitas }\end{array}$ \\
\cline { 3 - 6 } & 92 & Komunikasi $\left(\mathrm{X}_{1}\right)$ & 0,642 & 1,557 & Signifikansi \\
\hline $\mathrm{N}$ & 0,972 & $\begin{array}{l}\text { Budaya } \\
\text { organisasi }\left(\mathrm{X}_{2}\right)\end{array}$ & 0,687 & 1,455 & 0,753 \\
\hline $\begin{array}{c}\text { Kolmogorov }- \\
\text { Smirnov } Z\end{array}$ & 0,302 & $\begin{array}{l}\text { Lingkungan kerja } \\
\left(\mathrm{X}_{3}\right)\end{array}$ & 0,751 & 1,332 & 0,880 \\
\hline $\begin{array}{c}\text { Asymp.Sig.(2- } \\
\text { tailed) }\end{array}$ & & & & \\
\hline
\end{tabular}

Sumber: Data diolah, 2018

Seluruh uji asumsi klasik dalam Tabel 10 sudah terpenuhi, maka selanjutnya memaparkan hasil analisis regresi linier berganda. Perhitungan koefisien regresi linier berganda dilakukan dengan analisis regresi melalui software SPSS 18.0 for Windows, diperoleh hasil yang ditunjukan pada Tabel 11.

Tabel 11.

Rangkuman Hasil Analisis Regresi Linier Berganda

\begin{tabular}{|c|c|c|c|c|c|}
\hline \multirow[t]{2}{*}{ Model } & \multicolumn{2}{|c|}{$\begin{array}{l}\text { Unstandardized } \\
\text { Coefficients }\end{array}$} & $\begin{array}{l}\text { Standardized } \\
\text { Coefficients }\end{array}$ & \multirow[b]{2}{*}{$\mathrm{t}$} & \multirow[b]{2}{*}{ Sig. } \\
\hline & B & Std. Error & Beta & & \\
\hline $\begin{array}{ll}1 & \text { (Constant) }\end{array}$ & 2,165 & 1,587 & & 1,365 & 0,176 \\
\hline Komunikasi & 0,274 & 0,100 & 0,234 & 2,737 & 0,007 \\
\hline Budaya Organisasi & 0,385 & 0,070 & 0,456 & 5,524 & 0,000 \\
\hline Lingkungan Kerja & 0,360 & 0,113 & 0,252 & 3,182 & 0,002 \\
\hline R Square & & & & & 0,587 \\
\hline Adjusted R Square & & & & & 0,573 \\
\hline F Hitung & & & & & 41,663 \\
\hline Signifikansi Uji F & & & & & 0,000 \\
\hline
\end{tabular}

Sumber : Data primer diolah, 2018

Berdasarkan hasil rangkuman analisis regresi linier berganda seperti yang disajikan pada Tabel 11, maka dapat dilihat besarnya pengaruh variabel bebas terhadap variabel terikat yang ditunjukkan oleh nilai determinasi total (Adjusted $\mathrm{R}$ Square) adalah sebesar 0,573 mempunyai arti bahwa sebesar 57,3\% variasi kepuasan kerja pegawai Hotel Ramada Bintang Bali Resort and Spa dipengaruhi oleh variasi komunikasi, budaya organisasi, dan lingkungan kerja, sedangkan 
sisanya sebesar $42,7 \%$ djelaskan oleh faktor lain yang tidak dimasukkan ke dalam model.

Hasil uji F (Ftest) pada Tabel 11 menunjukkan bahwa nilai signifikansi $\mathrm{P}$ value 0,000 yang lebih kecil dari $\alpha=0,05$, ini berarti model yang digunakan pada penelitian ini adalah layak. Hasil ini memberikan makna bahwa seluruh variabel independen mampu memprediksi atau menjelaskan fenomena kepuasan kerja pegawai Hotel Ramada Bintang Bali Resort and Spa. Hal ini berarti model dapat digunakan untuk analisa lebih lanjut atau dengan kata lain model dapat digunakan untuk memproyeksikan karena hasil goodness of fitnya baik dengan nilai signifikansi $\mathrm{P}$ value 0,000. Hal ini memberikan informasi bahwa terdapat pengaruh secara simultan dari variabel komunikasi, budaya organisasi, dan lingkungan kerja terhadap kepuasan kerja pegawai.

Berdasarkan hasil analisis pengaruh komunikasi terhadap kepuasan kerja pada Tabel 11 diperoleh nilai signifikasi sebesar 0,007 dengan nilai koefisien beta 0,274. Nilai Signifikansi $0,007<0,05$ mengindikasikan bahwa $\mathrm{H}_{0}$ ditolak dan $\mathrm{H}_{1}$ diterima. Hasil ini mempunyai arti bahwa Komunikasi berpengaruh positif dan signifikan terhadap Kepuasan kerja pegawai Hotel Ramada Bintang Bali Resort and Spa. Semakin baik komunikasi yang terjadi di Hotel Ramada Bintang Bali Resort and Spa maka akan semakin tinggi kepuasan kerja yang dirasakan pegawai. Begitu pula sebaliknya, semakin buruk komunikasi yang terjadi pada Hotel Ramada Bintang Bali Resort and Spa, maka akan semakin mengurangi kepuasan kerja yang dirasakan pegawai. 
Komunikasi merupakan bagian yang penting dalam kehidupan kerja. Hal ini mudah dipahami sebab komunikasi yang tidak baik bisa mempunyai dampak yang luas terhadap kehidupan organisasi, misal konflik antar pegawai, dan sebaliknya komunikasi yang baik dapat meningkatkan saling pengertian, kerjasama dan juga kepuasan kerja. Mengingat yang bekerjasama dalam suatu organisasi dalam rangka mencapai tujuan merupakan sekelompok sumber daya manusia dengan berbagai karakter, maka komunikasi yang terbuka harus dikembangkan dengan baik. Komunikasi memiliki hubungan yang positif terhadap kepuasan kerja karyawan, yaitu semakin baik proses komunikasi yang dilakukan akan membuat kepuasan kerja semakin meningkat (Mustika, 2013).

Penelitian ini mendukung beberapa hasil penelitian sebelumnya dan konsisten dengan hasil penelitian yang dilakukan oleh Shakil (2012), Epure et al. (2013), Diatmika (2013), Siregar (2014), Riadi (2015), Wirawan dan Sudharma (2015), Supriambodo (2016), Riyadi dkk. (2017), serta Harahap dan Mahadewi (2017) yang memperoleh hasil bahwa komunikasi berpengaruh positif dan signifikan terhadap kepuasan kerja pegawai yang berarti semakin baik komunikasi yang dilakukan maka kepuasan kerja pegawai akan mengalami peningkatan.

Berdasarkan hasil analisis pengaruh budaya organisasi terhadap kepuasan kerja pada Tabel 11 diperoleh nilai signifikansi sebesar 0,000 dengan nilai koefisien beta 0,385 . Nilai Signifikansi $0,000<0,05$ mengindikasikan bahwa $\mathrm{H}_{0}$ ditolak dan $\mathrm{H}_{2}$ diterima. Hasil ini mempunyai arti bahwa Budaya organisasi berpengaruh positif dan signifikan terhadap Kepuasan kerja pegawai Hotel Ramada Bintang Bali Resort and Spa. Semakin kuat budaya organisasi yang 
terbentuk di Hotel Ramada Bintang Bali Resort and Spa maka kepuasan kerja karyawan akan semakin meningkat. Begitu pula sebaliknya, semakin lemah budaya organisasi yang terbentuk di Hotel Ramada Bintang Bali Resort and Spa maka semakin rendah tingkat kepuasan kerja pegawai tersebut.

Budaya organisasi yang didalamnya terkandung nilai, sikap, keyakinan, dan norma-norma yang dianut oleh anggota organisasi akan berpengaruh pada efektivitas organisasi dan kepuasan kerja anggota organisasi tersebut. Dengan demikian nilai-nilai dan norma-norma yang dianut oleh seseorang yang bekerja pada organisasi syariah juga akan berpengaruh pada kepuasan kerjanya (Refi, 2015).

Penelitian ini mendukung beberapa hasil penelitian sebelumnya dan konsisten dengan hasil penelitian Abadiyah dan Purwanto (2016) yang memperoleh hasil bahwa budaya organisasi berpengaruh terhadap kepuasan kerja. Bila perusahaan memiliki budaya organisasi yang tinggi, diharapkan pegawai akan lebih disiplin dan mampu menyelesaikan tugas dengan cepat dan tepat sehingga timbul kepuasan kerja. Penelitian ini juga di dukung oleh hasil penelitian Lestari dan Hutami (2014), Susetyo dkk. (2014), Herawan dkk. (2015), Yusuf (2016), Lagonah dkk. (2016), serta Wibowo dan Putra (2016) menemukan hasil bahwa budaya oganisasi berpengaruh positif dan signifikan terhadap kepuasan kerja. Hal ini berarti bahwa semakin baik penerapan budaya organisasi maka akan semakin mendorong terbentuknya kepuasan kerja karyawan

Berdasarkan hasil analisis pengaruh lingkungan kerja terhadap kepuasan kerja pada Tabel 11 diperoleh nilai signifikansi sebesar 0,002 dengan nilai 
koefisien beta 0,360 . Nilai signifikansi $0,002<0,05$ mengindikasikan bahwa $\mathrm{H}_{0}$ ditolak dan $\mathrm{H}_{3}$ diterima. Hasil ini mempunyai arti bahwa Lingkungan kerja berpengaruh positif dan signifikan terhadap Kepuasan kerja pegawai Hotel Ramada Bintang Bali Resort and Spa. Semakin baik kondisi lingkungan kerja maka akan berpengaruh pada semakin meningkatnya kepuasan kerja pegawai Hotel Ramada Bintang Bali Resort and Spa. Begitu pula sebaliknya, semakin buruk kondisi lingkungan kerja pada Hotel Ramada Bintang Bali Resort and Spa maka akan berpengaruh pada semakin berkurangnya kepuasan kerja pegawai.

Lingkungan kerja yang baik merupakan salah satu kondisi kerja yang mendukung. Karyawan membutuhkan lingkungan kerja yang baik, selain untuk kenyamanan juga sebagai faktor pendukung dalam melaksanakan pekerjaannya. Hal ini dapat menimbulkan rasa puas pada diri karyawan karena banyak faktor yang mendukung dalam bekerja (Pangestu dkk., 2017).

Penelitian ini mendukung beberapa hasil penelitian sebelumnya dan konsisten dengan hasil penelitian Wibowo dkk. (2014) yang menunjukkan bahwa lingkungan kerja fisik mempunyai pengaruh signifikan terhadap kepuasan kerja. Tingkat signifikansi memiliki makna bahwa lingkungan kerja fisik memiliki peranan yang penting utnuk meningkatkan kepuasan kerja. Hasil penelitian ini juga di dukung oleh Rumada dan Utama (2013), Riadi (2015), Wirawan dan Sudharma (2015), Aruan dan Fakhri (2015), Haedar dkk. (2015), Putri dkk. (2016), Yusuf (2016), Husni dkk. (2018) dan Sari (2018) yang menemukan hasil bahwa lingkungan kerja berpengaruh positif dan signifikan pada kepuasan kerja karyawan yang berarti semakin baik lingkungan kerja fisik, maka kepuasan kerja 
akan semakin meningkat. Lingkungan kerja yang baik dan terjaga akan membuat karyawan merasa tenang dan nyaman sehingga kepuasan kerja akan meningkat

\section{SIMPULAN DAN SARAN}

Berdasarkan hasil analisis penelitian dan hasil pembahasan maka simpulan dari penelitian ini yaitu : 1) Komunikasi berpengaruh positif dan signifikan terhadap kepuasan kerja. Hal ini berarti semakin baik komunikasi yang terjadi di Hotel Ramada Bintang Bali Resort and Spa maka semakin tinggi kepuasan kerja yang dirasakan pegawai. 2) Budaya organisasi berpengaruh positif dan signifikan terhadap kepuasan kerja. Hal ini berarti bahwa semakin kuat budaya organisasi yang terbentuk di Hotel Ramada Bintang Bali Resort and Spa maka kepuasan kerja karyawan akan semakin meningkat. 3) Lingkungan kerja berpengaruh positif dan signifikan terhadap kepuasan kerja. Hal ini berarti semakin baik kondisi lingkungan kerja maka akan berpengaruh pada semakin meningkatnya kepuasan kerja pegawai Hotel Ramada Bintang Bali Resort and Spa.

Saran yang dapat diberikan berdasarkan hasil penelitian adalah 1) Dalam upaya meningkatkan komunikasi menjadi lebih baik, maka Hotel Ramada Bintang Bali Resort and Spa sebaiknya memberikan pelatihan dan pendidikan bagi karyawannya mengenai cara berdiskusi yang tepat dalam menemukan solusi pada permasalahan kerja yang dihadapi. Apabila karyawan mampu berdiskusi dengan efektif dalam menemukan solusi permasalahan pekerjaan, maka komunikasi akan semakin baik. 2) Dalam upaya meningkatkan budaya organisasi pegawai, maka Hotel Ramada Bintang Bali Resort and Spa sebaiknya membuat sanksi yang lebih tegas bagi karyawan yang kurang disiplin dan tidak hadir tepat waktu dalam 
bekerja. Dengan pemberian sanksi yang tegas bagi karyawan yang melanggar, diharapkan dapat membuat karyawan jera sehingga budaya organisasi yang disiplin dapat terbentuk dengan baik. 3) Dalam upaya meningkatkan lingkungan kerja menjadi lebih baik, maka pihak manajemen Hotel Ramada Bintang Bali Resort and Spa sebaiknya rutin melakukan evaluasi terhadap fasilitas yang disediakan Hotel dalam menunjang pekerjaan karyawannya. Apabila ada fasilitas yang sudah rusak segera diperbaiki atau diganti, sehingga dapat membuat karyawan merasa nyaman dalam bekerja dan pada akhirnya dapat membentuk kepuasan kerja karyawan. 4) Dalam upaya meningkatkan kepuasan kerja pegawai menjadi lebih baik, maka pihak manajemen Hotel Ramada Bintang Bali Resort and Spa sebaiknya melakukan evaluasi pada gaji atau upah yang sudah diberikan pada karyawannya apakah sudah sesuai dengan beban kerja yang diterima. Apabila karyawan merasa puas dengan bayaran yang diberikan oleh perusahan karena sudah adil dan sudah sesuai sama beban kerja yang diterima, maka hal tersebut dapat meningkatkan kepuasan kerja karyawan

\section{REFERENSI}

Aruan, Quinerita Stevani dan Mahendra Fakhri. (2015). Pengaruh Lingkungan Kerja Terhadap Kepuasan Kerja Karyawan Lapangan Departemen Grasberg Power Distribution PT. Freeport Indonesia. Jurnal MODUS. 27(2): 141-162

Cekmecelioglu, Hulya Gunduz., Ayse Gunseland Tugce Ulutas. (2012). Effects Of Emotional Intelligence On Job Satisfaction: An Empirical Study On Call Center Employees. Procedia-Social and Behavioral Sciences, 58,pp: 363-369.

Diatmika, Paripurna. (2013). Pengaruh Lingkungan Kerja, Komunikasi Terhadap Kepuasan Kerja Karyawan. E-journal Manajemen Unud, 2 (5): 581-593 
Epure, Danut Tiberius., Alexandra Ionescu, and Dorinela Nancu. (2013). The Impact of Communication in Job Satisfaction: an Empirical Investigation within Romanian Companies. Journal Economics and Applied Informatics. 19(2): 71-74

Haedar., Sharuddin, dan Herlangga. (2015). Pengaruh Lingkungan Kerja Dan Masa Kerja Terhadap Kepuasan Karyawan Pada PT. Hadji Kalla Palopo. Jurnal Manajemen. 2(1): 10-22

Harahap, Zulkifli., dan Ni Made Eka Mahadewi. (2017). Pengaruh Komunikasi Terhadap Kepuasan Kerja Karyawan Hotel (Studi Kasus Hotel Bintang 4 dan 5 di Destinasi Wisata Jawa Barat). Jurnal Kepariwisataan.16(1): 3546

Herawan, Koko., M. Djudi Mukzam, dan Gunawan Eko Nurtjahjono. (2015). Pengaruh Budaya Organisasi Terhadap Kepuasan Kerja Karyawan Studi Pada PT. Bank Rakyat Indonesia (Persero) Kantor Cabang Kota Malang Kawi. Jurnal Administrasi Bisnis. 18(1): 1-6

Husni., Said Musnadi, Faisal. (2018). Pengaruh Lingkungan Kerja, Kompensasi Dan Motivasi Terhadap Kepuasan Kerja Serta Dampaknya Terhadap Loyalitas Kerja Pegawai Rutan di Provinsi Aceh (Studi Kasus Pada Rutan Klas Iib Banda Aceh Dan Rutan Klas Ii B Jantho. Jurnal Magister Manajemen. 2(1):88-98

Julianto, Romi Haryo dan Susi Hendriani. (2014). Pengaruh Budaya Organisasi dan Motivasi Kerja Terhadap Kepuasan Kerja dan Kinerja Pegawai Pada Kantor Wilayah Direktorat Jenderal Bea dan Cukai (DJBC) Riau dan Sumatera Barat. Jurnal Ekonomi. Vol. 22, No. 2, Hal: 13-26

Lagonah, Srijanti., Rianoe Pio, dan Markus Kaunang. (2016). Pengaruh Iklim Organisasi Dan Budaya Organisasi Terhadap Kepuasan Kerja Pegawai Kantor Pertanahan Kota Manado. Jurnal Ilmiah Society. 1(24): 1-19

Lestari, Anjani Puji., dan Rr. Rieka Febriyanti Hutami. (2014). Pengaruh Budaya Organisasi Terhadap Kepuasan Kerja Karyawan Telkom Foundation (TF). Jurnal Manajemen Bisnis Telekomunikasi dan Informatika. Pp: 1-8

Mariani, Luh Mang Indah., dan Ni Ketut Sariyathi. (2017). Pengaruh Motivasi, Komunikasi Dan Disiplin Kerja Terhadap Kinerja Karyawan Warung Mina Peguyangan Di Denpasar. E-Jurnal Manajemen Unud. 6(7): 35403569

Mustika. (2013). Analisis Pengaruh Komunikasi Organisasi dan Komitmen Keorganisasian Terhadap Kepuasan Kerja Karyawan PT. BTPN Tbk KCP Pasar Baru Merangin. Jurnal Dinamika Manajemen. 1(3): 215-224 
Pangestu, Zulfahmi Septian., Mochammad Djudi Mukzam dan Ika Ruhana. (2017). Pengaruh Lingkungan Kerja Terhadap Kepuasan Kerja (Studi pada Karyawan Perum Perhutani Ngawi). Jurnal Administrasi Bisnis (JAB). 43(1):157-162

Putri, Sari Dewi. (2016). Pengaruh Lingkungan Kerja Terhadap Kepuasan Kerja Karyawan Hotel Grand Rocky Bukittinggi. E-Journal Home Economic and Tourism. 13(3): 1-17

Refi, Teuku Muana. (2015). Pengaruh Budaya Organisasi Terhadap Kepuasan Kerja Karyawan Bank Syariah Mandiri Cabang Banda Aceh. Jurnal Ekonomi Manajemen Dan Bisnis. 3(1):475-486

Riadi, Aris. (2015). Pengaruh Komunikasi Dan Lingkungan Kerja Terhadap Kepuasan Kerja Karyawan Pada PT. Mitra Indonesia Makmur Sejahtera. Jurnal Forum Ilmiah Pendidikan Akuntansi. 3(1): 1-10

Riduwan dan Sunarto, (2007), Pengantar Statiska Untuk Penelitian Pendidikan, Sosial, Ekonomi, dan Bisnis, Penerbit alfabeta, Bandung.

Riyadi, Heru., Bambang Sapto Utomo, dan Anwari Masatip. (2017). Pengaruh Komunikasi, Motivasi Kerja dan Kompetensi Terhadap Kepuasan Kerja Serta Implikasinya Pada Kinerja Dosen Pada Perguruan Tinggi Pariwisata Swasta Di Jawa Barat. Tourism and Hospitality Essentials (THE) Journal. 7(2): 73-90

Rumada, Gede dan Utama, Mudiartha, (2013). Pengaruh Kompensasi, Lingkungan Kerja Fisik Terhadap Kepuasan Kerja Karyawan Hotel Taman Harum Ubud Gianyar.E-Jurnal Manajemen Universitas Udayana, 2(1): 106-120

Santoso, Agus. (2018). Pengaruh Efikasi Diri, Motivasi Kerja, Dan Lingkungan Kerja Terhadap Kepuasan Kerja Pegawai PT. Sukanda Djaya Cabang Denpasar. E-Jurnal Manajemen Universitas Udayana, 7(10): $1617-1643$

Sari, Dewi Puranama. (2018). Pengaruh Lingkungan Kerja Dan Disiplin Kerja Terhadap Kepuasan Kerja Guru Sekolah Menengah Kejuruan (SMK) Swasta Sekecamatan Pondok Aren. Jurnal Saintika Unpam. 1(1):108-132

Shakil, M. Ahmad. (2012). Impact Of Organizational Culture On Performance Management Practices in Pakistan. Bussines Intelligence Journal. 5(1) : p: $50-55$.

Siregar, Siti Zubaidah. (2014). Pengaruh Budaya Organisasi dan Komunikasi Terhadap Kepuasan Kerja Serta Dampaknya Pada Kinerja Guru Sekolah Dasar Negeri di Kota Sibolga. Tesis. Universitas Terbuka. 
Sugiyono. (2016). Metode Penelitian Kuantitatif Kualitataif dan Kombinasi (Mixed Methods). Bandung: Alfabeta.

Supriambodo, Agung. (2016). Pengaruh Komunikasi Terhadap Kepuasan Kerja Karyawan (Studi Pada CV Solaris Service Sentosa Kota Sidoarjo). Jurnal Ilmu Sosial dan Ilmu Politik Universitas Muhammadiyah, hal:1-28

Susetyo, Widyanto Eko., Amiartuti Kusmaningtyas, dan Hendro Tjahjono. (2014). Pengaruh Budaya Organisasi Dan Lingkungan Kerja Terhadap Kepuasan Kerja Dan Kinerja Karyawan Pada PT. Bank Muamalat Indonesia Divisi Konsumer Area Cabang Surabaya. Jurnal Ilmu Ekonomi \& Manajemen. $1(1), 83-93$

Suryaningsih, Eka Putri, (2012). Pengaruh Budaya Organisasi, Komunikasi dan Lingkungan Fisik Terhadap Kepuasan Kerja Karyawan Pada Ramada Bintang Bali Resort and Spa di Kuta Kabupaten Badung. Jurnal Manajemen. Fakultas Ekonomi Universitas Warmadewa. Hal:1-6

Wibowo, Mukti., Mochammad Al Musadieq dan Gunawan Eko Nurtjahjono. (2014). Pengaruh Lingkungan Kerja Terhadap Kepuasan Kerja Karyawan (Studi pada Karyawan PT. Telekomunikasi Indonesia Tbk. Kandatel Malang). Jurnal Administrasi Bisnis (JAB). 16(1): 1-9

Wibowo, Mada Adi., dan Yanuar Surya Putra. (2016). Pengaruh Motivasi Dan Budaya Organisasi Terhadap Kepuasan Kerja Serta Implikasinya Terhadap Kinerja Karyawan Pada Rumah Sakit Umum (RSU) Salatiga. Jurnal Ilmiah Among Makarti. 9(17): 1-20

Wirawan, I Dewa Gede Kresna., dan I Nyoman Sudharma. (2015). Pengaruh Komunikasi, Motivasi dan Lingkungan, Kerja Fisik Terhadap Kepuasan Kerja Pegawai Sekretariat Daerah Kota Denpasar. E-Jurnal Manajemen Unud. 4(10): 3037-3062.

Yusuf, Muhammad. (2016). Pengaruh Gaya Kepemimpinan Dan Budaya Organisasi Terhadap Kepuasan Kerja Dan Kinerja Guru Militer Resimen Induk Komando Daerah Militer Vii/Wirabuana Di Sulawesi. Jurnal Bisnis dan Kewirausahaan. 5(2): 219-236 